Article

\title{
The Oxygen Transport Triad in High Altitude Pulmonary Edema: a Perspective from the High Andes
}

\author{
Gustavo Zubieta-Calleja ${ }^{1 *}$, and Natalia Zubieta-DeUrioste ${ }^{1}$
}

1 High Altitude Pulmonary and Pathology Institute (HAPPI-IPPA); zubieta@altitudeclinic.com

* Correspondence: gzubietajr@altitudeclinic.com; Tel.: 591-73258026

\begin{abstract}
Acute high altitude illnesses are of great concern for physicians and people traveling to high altitude. High Altitude Pulmonary Edema (HAPE) can be better understood through the Oxygen Transport Triad which involves the Pneumo-Dynamic Pump (Ventilation), the Hemo-Dynamic Pump (Heart and circulation), and Hemoglobin. The two pumps are the first physiologic response upon initial exposure to hypobaric hypoxia. Hemoglobin is the balancing energy-saving time-evolving equilibrating factor. The increased hemoglobin at high altitude reduces the percentage of dissolved oxygen in the arterial oxygen content with respect to sea level. At high altitude, the acid-base balance must be adequately interpreted using the high altitude Van-Slyke correction factors. Pulse-oximetry measurements during breath-holding at high altitude allow for the evaluation of high altitude diseases. The Tolerance to Hypoxia Formula shows that, paradoxically, the higher the altitude the more tolerance to hypoxia. All organisms adapt physiologically and optimally to a high-altitude environment to survive. A favorable evolution in HAPE pulmonary hypertension can result from the oxygen treatment along with other measures.
\end{abstract}

Keywords: high altitude, chronic hypobaric hypoxia, physiologic adaptation, travel to high altitude cities, high altitude physiology, pulmonary hypertension, lung disease, hemoglobin, tolerance to hypoxia, oxygen content.

\section{Introduction}

Concerning our article entitled "Acute Mountain Sickness, High Altitude Pulmonary Edema, and High Altitude Cerebral Edema: A view from the High Andes"[1], we hereby include further comments with clarifications. This opinion article results from questions raised by "sea level high-altitude experts". It is based on our perspective as high altitude physicians with 50 years of experience at our High Altitude and Pulmonary Pathology Institute (HAPPI-IPPA), located in La Paz, Bolivia, 3,500m.

According to Dictionary.com, adaptation is defined as: "A change in structure, function, or behavior by which a species or individual improves its chance of survival in a specific (new) environment". We are aware that geneticists have previously defined "adaptation" solely as a process associated with genetic modifications. However, besides ourselves, several authors use the term physiologic adaptation in reference to high altitude [2,3]. We believe that adaptation should be defined based on two types: Genetic and Physiologic. "Genetic adaptation" as the process of alterations of form or behavior brought about through natural selection and genetic change (millions or thousands of years of molecular genetic evolution). "Physiologic adaptation" as the process of adjusting to environmental circumstances through epigenetic expressions and physiological immediate or delayed responses, making in-situ survival possible (in one lifetime). The epigenetic modifications 
(physiological adaptation) that change DNA expression at high altitude are well described [2]. "Biological adaptation" is a term used in seals' deep diving and breath-holding studies for over 1 hour [4].

The "solely genetic" adaptation concept has given rise to biased misinterpretations. One of them is the idea that high altitude hypoxia leads to progressive deterioration. Nevertheless, we disagree with this concept since over 200 million people live and work at high altitude with no threat over time. High altitude-generated disease is poorly understood thus far. This happens due to a poor understanding of the physics laws applied to biology in a chronic hypoxia environment.

Analogous is the erroneous idea that Chronic Mountain Sickness (CMS) patients at high altitude present a "Loss of Adaptation". There is a desperate and complicated search for genetic "malformations" in those patients. It is more appropriate to speak about "dysfunctional organs". This occurs at sea level or high altitude in reference to diseases. For example, Diabetes results from a dysfunctional pancreas. It is not a "loss of adaptation" at sea level. Chronic Mountain Sickness (CMS) is not an isolated disease but multiple diseases in the chronic hypoxic environment [5]. We think it would more accurately be denominated "Chronic Sicknesses in the Mountain" (CSM). Currently, we use the term "PolyErythrocythemia (Poly=many, Erythrocyt= Red Blood Cells, hemia=in blood", to describe these alterations physiologically [5].

Conversely, CMS results from dysfunctional lungs, heart, kidneys, carotid bodies, central hypoventilation, hemoglobin alterations, and/or perhaps others. But it cannot be referred to as a "Loss of adaptation" [5,6]. In Biology, aging is an irreversible forward process being impossible to grow younger. Analogously, in Physics, time is irreversible, except in theoretical estimations.

Sea level physicians and scientists occasionally visit high altitude to perform some studies and produce interesting results. However, to gain true expertise, it is most practical to spend a lifetime of studies living permanently in the chronic hypoxic environment found at high altitude. The adjacent cities of La Paz and El Alto are located between 3,100 and $4,100 \mathrm{~m}$ of altitude in Bolivia, in the "heart of South America". They are the highest cities in the world with over 2 million inhabitants https://www.visualcapitalist.com/the-50highest-cities-in-the-world/.

We have carried out the Chronic Hypoxia Symposiums every two years in La Paz, Bolivia, except for the 4th carried out in New Dehli, India. We have denominated La Paz the "Capital of Hypoxia" and the "Shrine of Hypoxia Scientists" since the 1st symposium in 2005 (https://zuniv.net/symposium/). During the 7th Chronic Hypoxia Symposium, Prof. Pavel Beloshitsky from Ukraine has also supported this denomination (https://zuniv.net/symposium7/Abstracts7CHS.pdf).

\section{High altitude physiology}

In our previous article[1], we provide a good review of high altitude physiology. We further extend some essential aspects. Breathing at high altitude, differs from breathing at sea level. The arterial oxygen saturation (SaO2) in pulse oximetry (SPO2) fluctuates with the change of breathing patterns and a deep breath increases alveolar oxygen tension [7]. This is only evident at high altitude as the $\mathrm{PaO} 2$ is located in the steep portion of the hemoglobin oxygen dissociation curve. At sea level, since the oxygen pressures are high and the oxygen dissociation curve is in the top plateau, those changes cannot be observed. In a high oxygen pressure as at sea level, a small change in arterial partial pressure of oxygen $(\mathrm{PaO} 2)$ does not change saturation $(\mathrm{SpO} 2)$. This is one fundamental factor that confuses sea level physiologists concerning high altitude. 


\section{The Oxygen Transport Triad}

We define the Oxygen Transport Triad with three components: the Pneumo-dynamic pump (an air vacuum pump), the Hemo-Dynamic (a blood compression pump), and hemoglobin (the iron oxygen porter molecule in the blood). In order for the reader to interpret the role of the Pneumo-dynamic (respiratory) and Hemo-dynamic (Cardio-vascular) pumps observed in our laboratory at $3500 \mathrm{~m}$ above sea level in La Paz, Bolivia, we developed, twenty-one years ago, a study measuring cardio-respiratory parameters under four conditions. This data was presented in a hypoxia conference organized by the Bogomoletz Physiology Institute in Ukraine in 2000. It is useful to explain the Oxygen Transport Triad.

The subject is studied first at rest 1) lying down, 2) sitting, 3) standing up, and then during a USAF modified exercise protocol (Fig. 1). Three resting positions were studied for 6 minutes each in 15 native residents. Ventilation was measured by pneumotachograph, pulse and saturation by pulse oximetry, and end-tidal $\mathrm{O}_{2}$ and $\mathrm{CO}_{2}$ from expired gas.

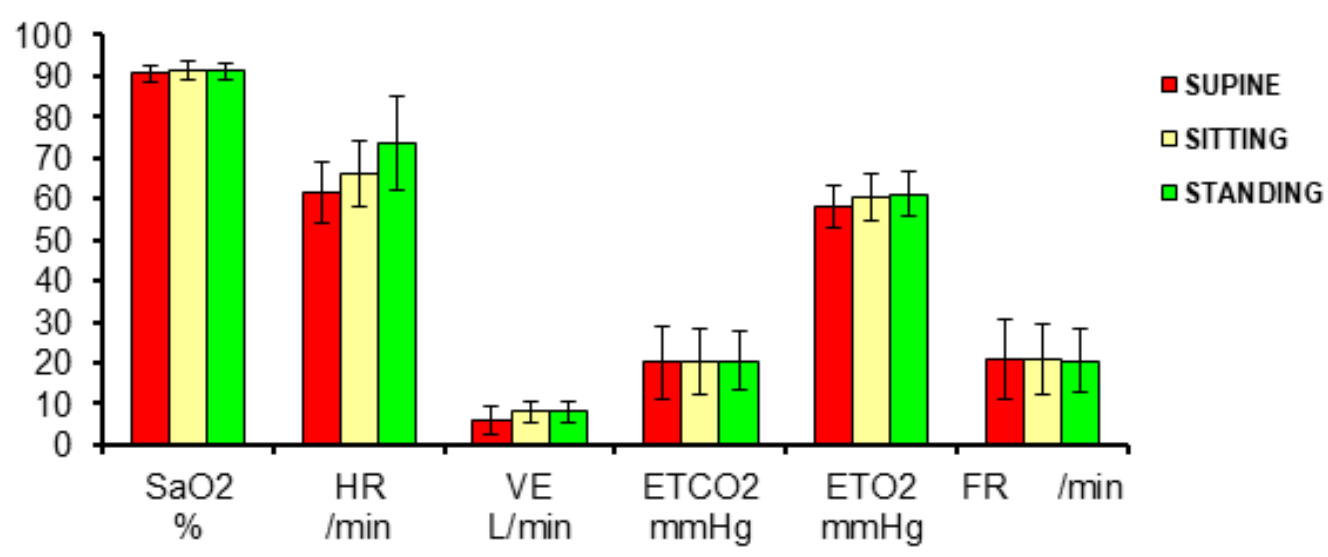

Figure 1. Ventilation and pulseoximetry studies in 3 positions: supine, sitting, standing at $3.500 \mathrm{~m}$ of altitude. $\mathrm{SaO} 2=$ Arterial Oxygen saturation from pulse oximeter, $\mathrm{Hr}=$ Heart rate, $\mathrm{VE}=$ Ventilation $(\mathrm{BTPS}), \mathrm{ETCO} 2=$ End-Tidal carbon dioxide, ETO2 End-tidal oxygen, FR = Respiratory Frequency.

While lying down, only the respiratory and cardiac muscles are active and constitute the basal metabolic rate (including the brain and all other organs' basal oxygen consumption). In the sitting and standing positions, the Pneumo-dynamic pump and the Hemodynamic pump gradually increase ventilation and heart rate, respectively, to maintain the oxygen saturation related to the arterial blood oxygen content. The change of positions requires the use of additional orthostatic muscles and hence greater oxygen consumption. While sitting down, some muscles in the back are involved in maintaining the thorax up, whereas standing up, the orthostatic muscles of the legs and thighs add up. In all three positions, the brain and all other organs maintain a similar oxygen consumption. The oxygen consumption is adequately compensated for the gradually increasing metabolic requirement in the three resting positions keeping SpO2 within normal limits. During exercise at different incremental work levels, the $\mathrm{SpO} 2$ is steadily reduced due to increased oxygen consumption (Fig.2). It is interesting to point out that in space flight humans do 
not use the orthostatic muscles, and consequently, the hematocrit reduces [8], and it is a crucial BioSpaceForming factor $[9,10]$.

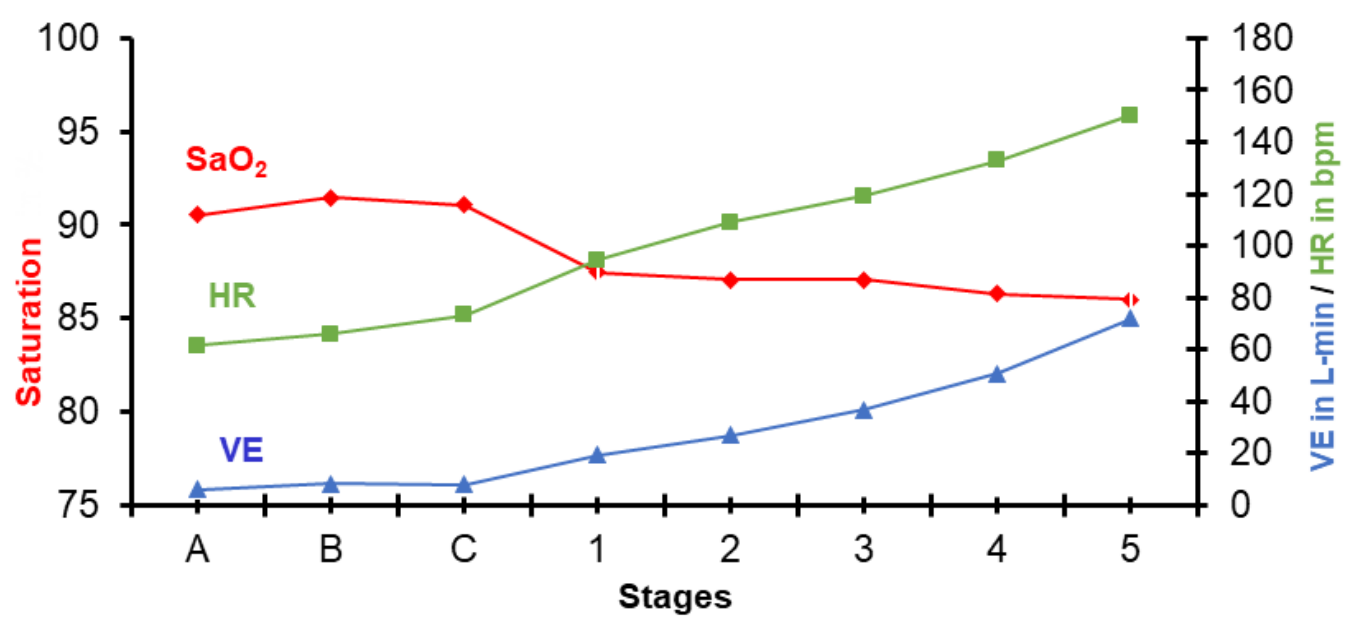

Figure 2. Oxygen Saturation obtained by pulse-oximetry, heart rate (HR) and ventilation (VE) in BTPS during the three resting stages A) Supine, B) Sitting C) Standing and then during 5 stages of exercise.

When the pumps are not fully effective (dysfunctional), as in cardio-pulmonary disease, the saturation drops; however, the oxygen content is maintained by increasing the number of red blood cells (hemoglobin and hematocrit). This is fundamental in the chronic hypobaric hypoxic environment at high altitude. Polyerythrocythemia (Poly = many, erythrocyte $=$ red blood cells, hemia = in the blood) is the terminology we use instead of Chronic Mountain Sickness (CMS). Comparing these results ( $\mathrm{Ht}=50 \%$ in 15 subjects) with one patient with Poly-erythrocythemia $(\mathrm{Ht}=72 \%)$ shows that the latter has a lower SpO2 at rest due to some cardiac or pulmonary disease, where the hematocrit (the 3rd Oxygen Transport factor), rises to compensate for the deficiency. The two pumps work similarly to those of the normal hematocrit residents, but the SpO2 is decreased. However, the test follows a similar behavior with a progressive reduction of SpO2 (Fig.3).

These studies are valuable for the diagnosis of cardio-pulmonary disease at high altitude. They show that CMS or rather Poly-erythrocythemia (PEH) is considered a single illness erroneously, actually being multiple diseases that compensate cardio or respiratory inefficiency (organ dysfunction) by increasing the red blood cells[5]. However, regardless of the elevated hematocrit, exercise is carried out and achieved as well as normal residents at 3,500m. This was observed by several authors [11,12].

It is important to note that the Oxygen Transport Triad "moves" oxygen from the environment to the lungs with the vacuum produced in the Pneumo-dynamic pump[13] (the lungs). Oxygen is then transferred through the alveolar-capillary membrane by "diffusion and only by diffusion", quoting the great August Krogh [14]. Oxygen is subsequently captured by hemoglobin. Thereafter, the Hemo-dynamic pump moves the hemoglobin oxygen-filled blood through a compression mechanism (the heart) to the tissue capillaries. The diffusion process repeats itself at the cellular level to reach mitochondria. At any altitude, Biology follows the laws of Physics at each stage (Fig. 4). 


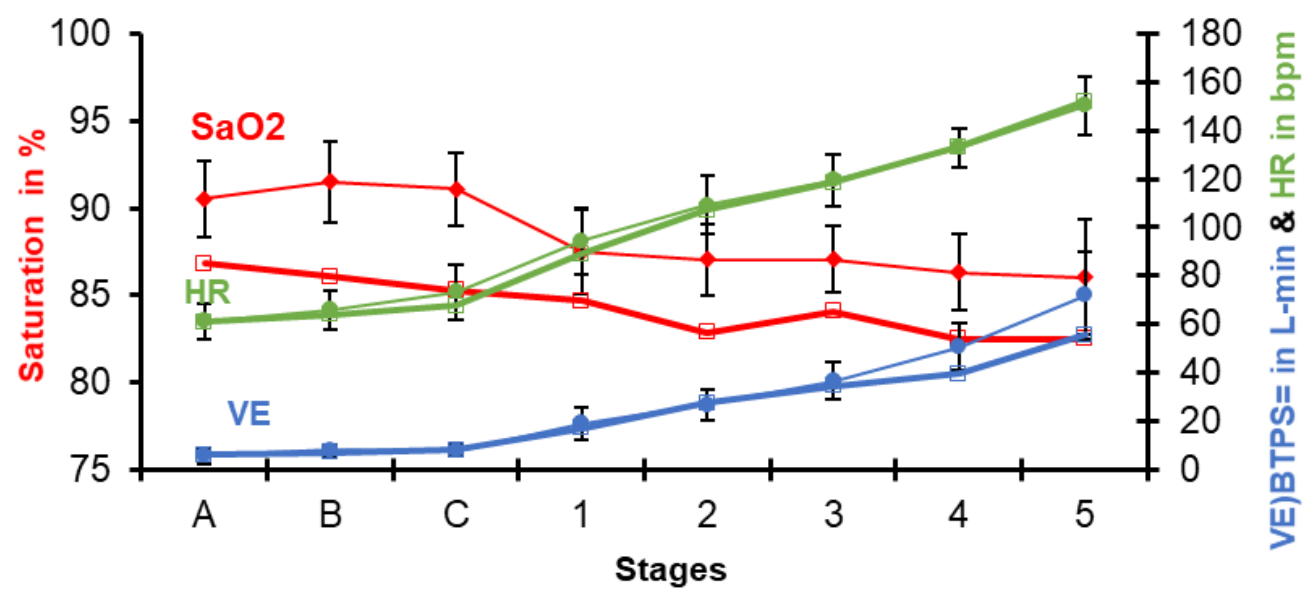

Figure 3. Same procedure as in Figure 2. This time comparing it with a patient with CMS (PEH) in thick lines.

\section{Oxygen Transport Triad \& the Laws of Physics}

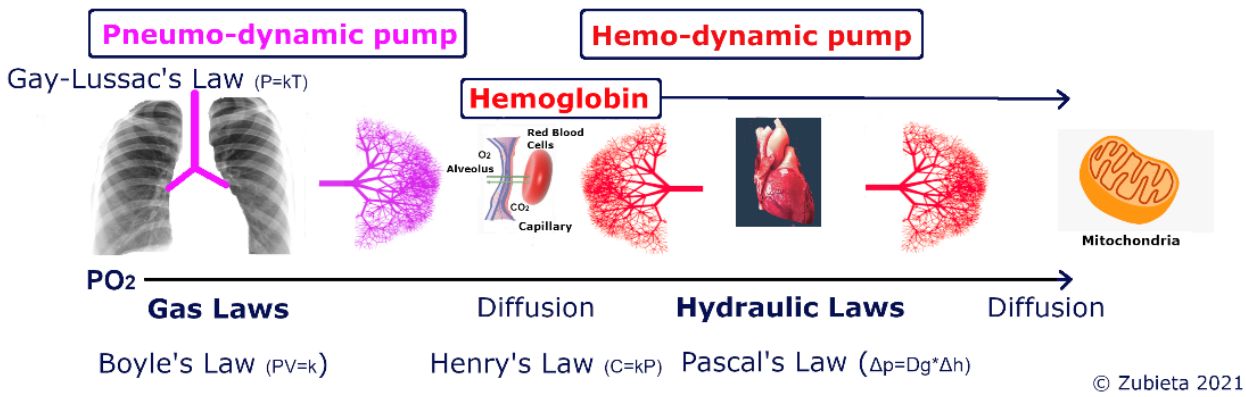

Figure 4. The Oxygen Transport Triad involves: The pneumo-dynamic pump->alveolar-capillary diffusion->the cardio-dynamic pump->capillary-mitochondrial diffusion. Note that each step involves one of the gas laws and the hydraulic Pascal's law.

\section{The arterial oxygen content $(\mathrm{CaO} 2)$ at high altitude}

The Arterial Oxygen Content in the blood can be calculated from:

$(\mathrm{CaO} 2)=(\mathrm{SaO} 2 \times 1.34 \times \mathrm{Hb})+(0.003 \times \mathrm{PaO} 2)$.

(O2 in Hemoglobin $)+($ Dissolved O2 in plasma $)$

It is important to note here that the miracle molecule hemoglobin transports practically all the arterial oxygen content in the blood. Interestingly, at sea level with the values $\mathrm{SaO} 2=99 \%, \mathrm{Hb}=15 \mathrm{gm} / \mathrm{dl}$ and $\mathrm{PaO} 2=100 \mathrm{mmHg}$, the $\mathrm{CaO} 2=20 \mathrm{Vol} \% \mathrm{O} 2$ and Hemoglobin transports $98.45 \%$ of the oxygen. Breathing ambient air at sea level $(760 \mathrm{mmHg})$, the dissolved oxygen portion of the $\mathrm{CaO} 2$ constitutes only $1.55 \%$ of the total oxygen content. Whereas at high altitude $3,500 \mathrm{~m}(495 \mathrm{mmHg})$, with the normal values of $\mathrm{SaO} 2=90 \%$, $\mathrm{Hb}=17 \mathrm{gm} / \mathrm{dl}$ and $\mathrm{PaO} 2=60 \mathrm{mmHg}$, the $\mathrm{CaO} 2=20.50 \mathrm{Vol} \% \mathrm{O} 2$ (higher than at sea level) 
Hemoglobin transports $99.13 \%$ of the oxygen whereas dissolved oxygen only $0.87 \%$ (Half of that at sea-level). Hence the importance of hemoglobin's elevation at high altitude for efficient oxygen transport [15].

\section{The Ferromagnetism of Iron in hemoglobin and the paramagnetic property of oxygen}

Iron is the most stable element in the universe. It is linked to globin forming the wellstudied complex hemoglobin molecule. It is important to note that oxygen, the fundamental element of respiration and hence life, is linked to the most stable element iron. Deoxygenated hemoglobin is paramagnetic whereas oxygenated hemoglobin is diamagnetic [16]. Oxygen has paramagnetic properties, being captured by electromagnets in its liquid form (for visualization). Some of the most efficient fast oxygen sensors are based on these paramagnetic characteristics. At high altitude there is higher hemoglobin as a compensating hypobaric environmental oxygen pressure[15]. With a more elevated hematocrit, it is possible that the paramagnetic properties of deoxygenated hemoglobin increase, thereby facilitating the capture of oxygen. This needs to be studied.

\section{The High Altitude Adaptation Formula}

Concerning the High Altitude Adaptation formula that we created:

$$
\text { Adaptation }=\text { time/altitude } \Delta
$$

It is a fundamental concept of adaptation to high altitude: as one travels higher (greater altitude change $(\Delta)$ ), more time is needed to achieve an adequate physiological adaptation. It refers to the hemoglobin rise where "Full hematological adaptation to high altitude is achieved when the increase of red blood cells reaches a plateau and stops". Hemoglobin increases logarithmically increasing over time. In other words, the organism wisely decides to increase the number of red blood cells to optimal levels, thereby reducing the extra load and energy-consuming hyperventilation (pneumo-dynamic pump) and tachycardia (hemo-dynamic pump). We have termed this "the most energy-efficient adaptation mechanism to high altitude" even in Chronic Mountain Sickness [17]. Gustavo ZubietaCastillo Sr (1926-2015) wrote a transcendental concept from where this adaptation formula derives:

"The organic systems of human beings and all other species tend to adapt to any environmental change and circumstance within an optimal period of time, and never tend towards regression which would inevitably lead to death" [5]. Regression would be equivalent to "Loss of Adaptation" a wrong interpretation, often used.

\section{Acid-Base balance at high altitude}

Another important aspect related to physiologic adaptation is the acid-base status of blood. It plays an essential role at high altitude, but unfortunately, it is poorly understood. There is the erroneous belief among sea-level physiologists that all high altitude residents live in an altered acid-base status characterized as Respiratory Alkalosis, based solely on the decrease of the arterial partial pressure of carbon dioxide (PaO2). This is a wrong concept as all high altitude inhabitants have to adapt and live in a perfectly balanced acidbase status. Thousands of metabolic and enzymatic reactions in cells require a perfectly balanced $\mathrm{pH}=7.4$. The body achieves this by decreasing blood bicarbonate (HCO3) due to the decrease of PaCO2 at high altitude [18]. We established the Van Slyke formula's correction factors at high altitude to adequately interpret acid-base following the Ole Siggaard-Andersen sea level concepts [18]. This is why we wrote an article questioning how over 200 million high altitude inhabitants on planet Earth could live permanently in an 
altered acid-base status [19]. We, likewise, questioned the use of sea-level interpretation of acid-base status on arterial blood gas samples taken at $8000 \mathrm{~m}$ near the summit of Mt. Everest [20]. In that article, the Base Excess (BE) for the 4 Mount Everest climbers was calculated as an average to be $-6.9 \mathrm{mM}$, using sea-level parameters. This is an abnormal acid-base status. However, using our correction factors, it was possible to demonstrate a normal acid-base status in the successful climbers of the world's highest peak [21]. THID (Titratable Hydrogen Ion Difference $=-B E$ ) was calculated to be $0.7 \mathrm{mM}$, close to a perfect acid-base balance of " 0 ". Such values are excellent for optimal cellular metabolism and enzymatic reactions. To the best of our knowledge, no other possible explanation, up-todate, exists to explain a successful climb to the summit of Mt. Everest. Consequently, Acid-Base balance plays a fundamental role in acute high altitude diseases, but it has to be adequately interpreted following our guidelines[18].

\section{Variations of pulse-oximetry at high altitude}

One of the fundamental measurements in high altitude medicine is pulse-oximetry. Since $\mathrm{SpO} 2$ at high altitude is located in the sloped part of the hemoglobin oxygen dissociation curve, breathing variations can increase pulse-oximetry changes. This is why it is important to show those variations with a breath-holding test we developed [22]. It is essential to consider these variations when evaluating a person who is suffering from high altitude illness.

\section{The expansion of gases at high altitude}

Regarding the expansion of gases at high altitude: Joseph Hamel, a scientist from Geneva, was the first to describe high altitude flatus expulsion (HAFE). HAFE was also mentioned by the notable Paul Auerbach, the respected past-president of Wilderness and Environmental Medicine [23]. We propose a new terminology: HAGE (High Altitude Gas Expansion), based on the very fundamental Boyle's law of gases and pressures. At high altitude, all physics laws stand solid, playing an essential role in biological adaptation. We calculated the expansion of gases in the abdomen, which is very important. It was mentioned in an article on "the High Andes", National Geographic Magazine April 1987, Volume 171 No. 4, where Loren McIntyre interviewed Gustavo Sr. and Jr., referring to it as "breaking the wind".

Furthermore, it is essential to note that gases' distension upon arriving at high altitude is not a transient phenomenon. The ideal gas law $\mathrm{PV}=\mathrm{nRT}$ stands for any altitude. Metabolic gas output from GI digestive chemical reactions has to be the same at any altitude. However, due to the lower barometric pressure, the flatulence gas volume grows and is more prominent at high altitude permanently. Some believe that "once at a stable altitude, the differential pressure between the atmosphere and GI tract disappears," but this is incorrect as it only applies to non-organic things such as bottles or balloons. Biology is linked to the pressure laws of physics at any altitude. This concept helps explain what Frisancho has described as the Dolicomegacolon (a loop of intestine twists around itself and the mesentery that supports it, resulting in a bowel obstruction - often a medical-surgical emergency) quite common in high altitude natives residing at 3,800m or above [24,25].

\section{The Tolerance to Hypoxia Formula}

Acute exposure to hypobaric hypoxia is different than acute exposure to normobaric hypoxia. This has to do with the denominator of our formula:

Tolerance to hypoxia $=\mathrm{Hb} / \mathrm{PaCO} 2$. 
Several studies have found differences between hypobaric (high altitude) hypoxia and normobaric (sea level) hypoxia artificially produced through a reduced Inspired Fraction of Oxygen (FIO2)[26,27]. There are many confounding factors, but everyone seems to forget the role of a reduced $\mathrm{PaCO} 2$ at high altitude. This is a critical factor, as a lower PaCO2 gives rise to higher tolerance to hypoxia [28][29]. We have compared exercise studies in the city of La Paz, breathing ambient air and then simulating the Chacaltaya altitude of 5300m in our Hyperoxic/Hypoxic Adaptation Chamber. We then went to Chacaltaya, where our Glass Pyramid Laboratory (the highest in the world, easily accessible by road 2 hours from our institute located in La Paz, Bolivia). There we repeated the exercise studies in the same subjects, and we showed differences with the normobaric hypoxia at $3500 \mathrm{~m}$ in our lab in La Paz.

It is interesting to note that normobaric hypoxia is always referred to as a barometric pressure of $760 \mathrm{mmHg}$ at sea level. However, we live in La Paz with a barometric pressure of $494 \mathrm{mmHg}$. This is normobaria for us. From our perspective, it is normoxia because we are born, develop, practice sports, study, get married, reproduce, and live to old age at high altitude. Consequently, someone who has never gone to sea level considers himself to be living in a "normal normoxic normobaric environment". We consider going to sea level, exposure to "hyperoxia" and we have some difficulties adapting to sea level [8]. Those alterations could be termed Acute Sea Level Sickness (ASLS). The symptoms are sleepiness, edema in the lower limbs, hypotension, fatigue, and drowsiness. We have named the edema on going down to sea level as LAPE (Low Altitude Peripheral Edema) [30].

\section{The oxygen levels in the summit of Mt. Everest, The Triple Hypoxia Syndrome, and Fetuses}

Babies in the maternal womb have a $\mathrm{PaO} 2$ of $30 \mathrm{mmHg}$ similar to that found at the summit of Mt. Everest[20]. They live at the hypoxic levels of Mt. Everest. Furthermore, Poly-erythrocythemia (Chronic Mountain Sickness) patients during the Triple Hypoxia Syndrome [39] have a PaO2 of $30 \mathrm{mmHg}$ or lower. They are living as though they were at the hypoxic levels of the summit of Mt. Everest. Every human being on planet earth has lived at the hypoxic levels found on top of Mt. Everest in the womb. According to our Tolerance to Hypoxia formula [28], a subject on the summit of Mt. Everest tolerates close to six times more hypoxia than a sea-level resident. The limiting factors for climbers to the summit of Mt. Everest are cold, fatigue, lack of sleep, and malnutrition. As expected, all these factors bring forth progressive physiological deterioration, but unfortunately, it is only attributed to hypoxia, a blind, biased sea-level approach.

\section{AMS evolving to HAPE and/or HACE}

Acute Mountain Sickness (AMS) results from exposure to acute hypoxia when ascending to a higher altitude. AMS symptoms are sleeping disorders, uneasiness, dehydration from hyperventilation and diminished thirst sensation, loss of appetite, and fatigue upon physical activities. When it pertains to arriving at a city like La Paz (3500m), perhaps it should be referred to as Acute Hypoxia Sickness (AHS). The term AMS refers to all mountain (hypoxia) sickness on acute exposure. This would etymologically include High Altitude Pulmonary Edema (HAPE) and High Altitude Cerebral Edema (HACE) that also form part of the term "acute mountain sickness" but in a more severe or advanced form, in our criteria. Most HAPE and HACE patients manifest several of the AMS symptoms. HAPE can be preceded by AMS, although some would disagree. We consider that AMS is the first step, and it can be aggravated and evolve to the two more advanced forms and possibly lethal conditions: HAPE and HACE (Fig. 5). Not everyone has a headache in AMS, so it is not reasonable to discard the diagnosis of AMS if the headache is not present in HAPE. However, headaches are present in several HAPE patients, along with shortness of breath, cyanosis, anorexia, and general malaise. 


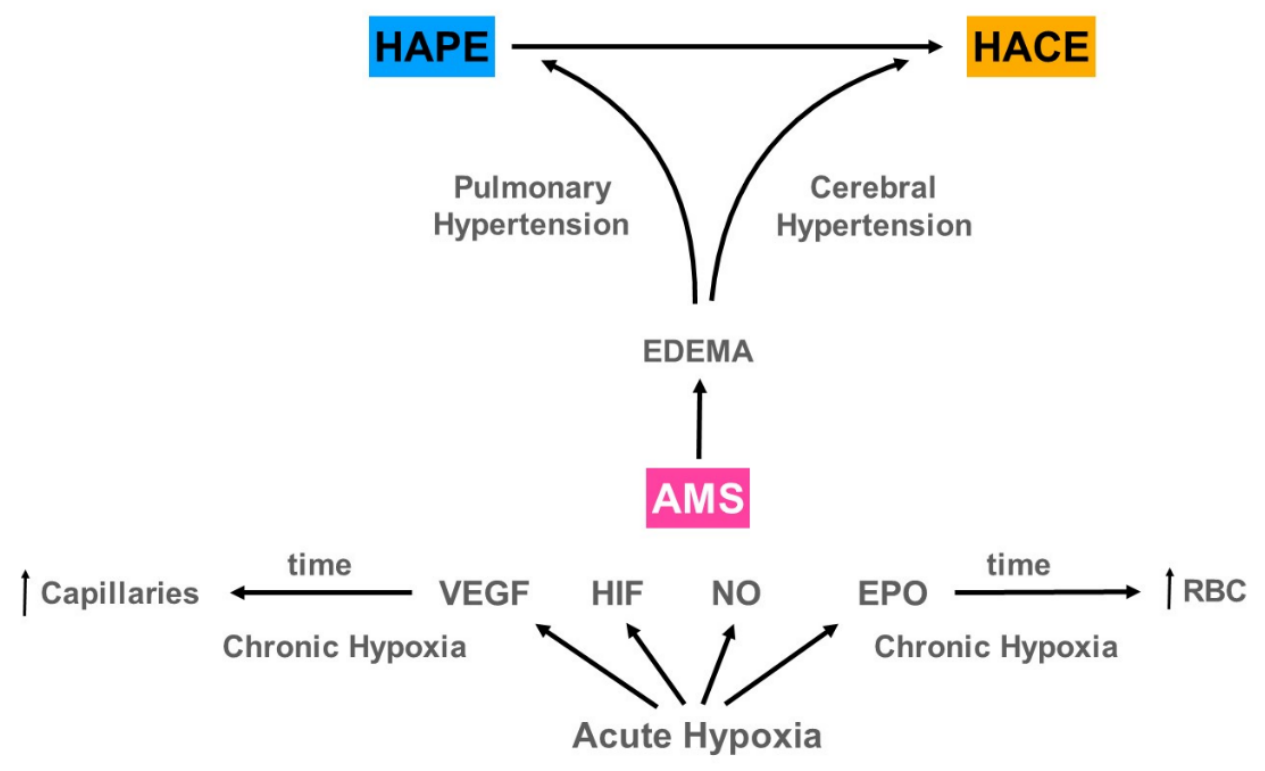

Figure 5. We postulate that AMS on exposure to high altitude hypoxia can evolve to either HAPE and/or HACE, and if there is no altitude illness the evolution towards an increase of Hemoglobin, Hematocrit and Red Blood Cells along with the formation of more capillaries, makes the organism of high altitude residents resistant to several diseases and leads to extended longevity.

\section{Treatment of HAPE and HACE at high altitude}

We are highly successful in our treatments of high-altitude diseases. We have saved all our high altitude patients' lives and saved travel insurance companies extraordinary expenses in the hundreds of thousands of dollars cost for airplane ambulances or millions of dollars for the loss of life. Rest is fundamental, yet we have never treated the patients solely with rest, although Marticorena and Hultgren wrote and published about the proven efficacy of rest in La Oroya [32]. Oxygen is basic and extremely important. Oxygen is the essential physiological pulmonary circulation vasodilator that rapidly reverses hypoxic pulmonary vasoconstriction. Pulmonary artery pressure typically returns to normal levels within minutes [33]. We have had success following our methods. And the article in reference [1] is a paper explaining our experience.

HIF is indeed a magnificent discovery by Semenza and co-workers [34-36], and it is fundamental in exposure to hypoxia. However, as with most mechanics in physiology, it depends on the dosage. And, in some cases, HIF has also been associated with side effects $[37,38]$.

\section{Pulmonary hypertension and a dilated right ventricle in (HAPE)}

In HAPE, the lungs present edema with a cotton image in Chest $X$-rays and Chest CAT scans (Fig. 6a). The pulmonary edema reduces the gas exchange surface area and produces aggravating hypoxia. This functional limitation has some similarity with COVID pneumolysis (pneumo=lung, lysis=destruction), where there is progressive silent hypoxemia until there is extreme hypoxia and hypercapnia [40]. Whereas post-COVID patients can 
have pulmonary fibrosis due to pneumolysis [13], in HAPE, recovery post-edema leaves no sequelae following prompt resolution within a few days (Fig. 6b).

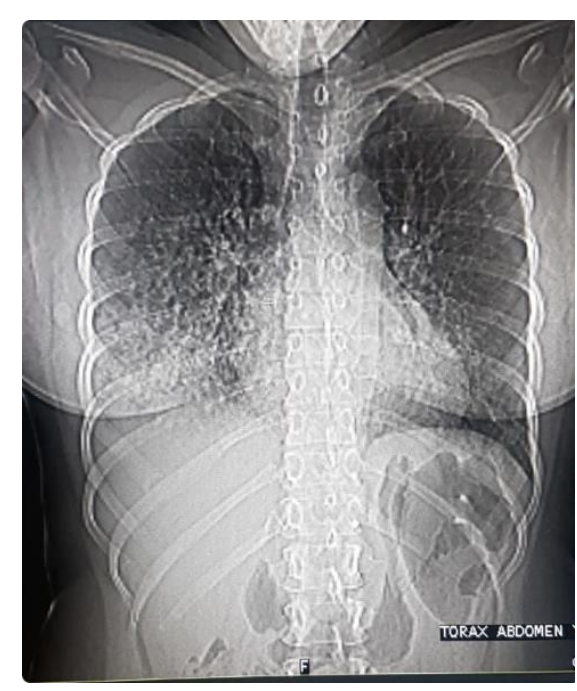

(a)

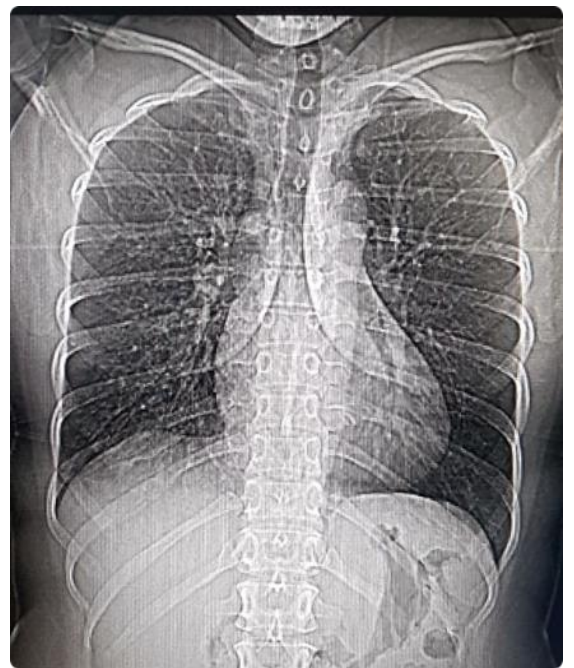

$(\boldsymbol{b})$

Figure 6. Thorax and Abdominal CAT Scans of a patient with HAPE at 3500m. (a) 4 days after arrival at high altitude. Note the distension of gases HAGE; (b) Two days later following the treatment described in our article [1].

HAPE presents with pulmonary hypertension that can be excessive in some people on exposure to hypoxia [41,42]. Furthermore, some individuals who previously presented HAPE were shown to have an excessive pulmonary vascular constriction not wholly responsive to oxygen administration [42], but nevertheless partially responsive and resulting in a favorable evolution. 


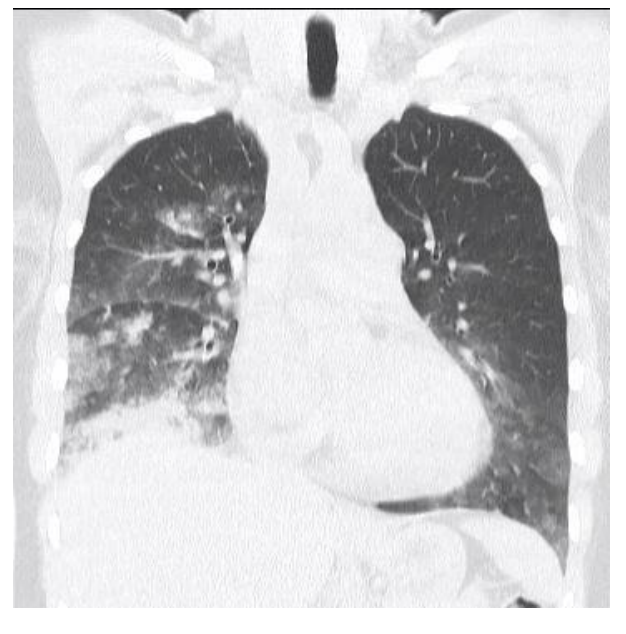

(a)

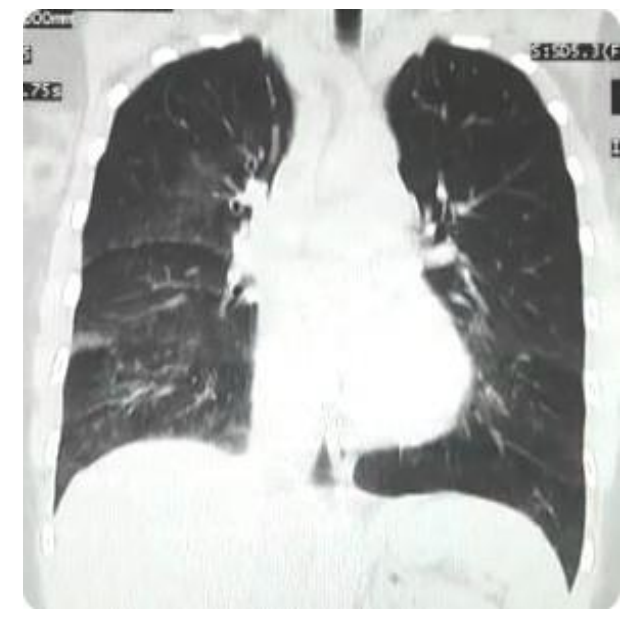

(b)

Figure 7. CAT scan of patient with HAPE. (a) Note the convex pulmonary arch due to pulmonary hypertension in the acute phase. The heart apex is likewise elevated due to dilatation of the right ventricle. (b) In the recovery stage of HAPE (2 days later during treatment) a decrease of the pulmonary arch can be observed at closely similar CAT scan coronal cut level (the size of the heart, due to systole or diastole, may have variations).

The electrocardiogram reports sinus tachycardia (increased activity of the hemo-dynamic pump) and usually a high pointed $\mathrm{P}$-wave (P-pulmonale) along with right axis deviation of QRS and a modified T-wave reflecting right ventricular overload [43]. The CAT scan shows an elevated heart apex due to the right ventricular dilatation. The high pointed Pwaves imply right atrial enlargement and are generally associated with pulmonary hypertension. Pulmonary hypertension is the hallmark reaction in HAPE [44] and hence the focus of oxygen treatment of HAPE. Blood circulation is shunted away from poorly oxygenated lung zones towards healthy alveoli to minimize V/Q mismatch upon exposure to high altitude hypoxia[45]. Echocardiography can show a dilated right ventricle and right atrium, as well as increased pulmonary artery pressure [46]. Chest X-ray and/or CAT scans can often show a convex pulmonary artery in the P-A projection (Fig. 7). In the city of La Paz, Bolivia, at 3,100-4,100m the Mean Pulmonary Artery Pressure (MPAP) is 23 $\mathrm{mmHg}$ [47]. Hence, pulmonary hypertension is a normal physiologic favorable response at high altitude in over 200 million inhabitants.

\section{Benefits of life under chronic hypoxia}

Chronic hypoxia is not "deleterious" but rather "beneficial". It gives us significant advantages: extended longevity[48], paradoxically greater tolerance to hypoxia as one goes higher[28], a creation of human plasticity with lower incidence of cardiac diseases[49], less obesity, less asthma[48,50], fewer hypertension problems, less lung cancer incidence [51,52], and even less COVID-19 incidence and lower Case Fatality Rate, as we had correctly predicted before the arrival of the Pandemic to Bolivia[13,53-57]. We believe sealevel dwellers have a severe survival disability: poor tolerance to hypoxia. Whereas, we, the highlanders, have achieved the first giant step, through physiologic adaptation to chronic hypoxia, of what we have termed BioSpaceForming (Adaptation to life in space)[10]. Humanity is preparing to colonize Mars. We foretell that humans in space will 
become a permanent chronic hypoxia species, which is why we have proposed that space travel should be carried out in a chronic hypoxia environment $[9,10]$.

\section{Conclusions}

High altitude illnesses are best evaluated by physicians working on-site, gaining experience over many years resulting in favorable recoveries as those expressed in this paper. High altitude biology follows physics laws, which apply to the distention of gases, the partial pressures of oxygen and carbon dioxide, and the acid-base balance. The treatment of high altitude illness becomes easier when there is a profound knowledge of high altitude physiology and the Oxygen Transport Triad. The high altitude pulmonary hypertension is normal response aiding in oxygen exchange at high altitude.

\section{Supplementary Materials: None}

Author Contributions: Both authors contributed equally.

Funding: This research received no external funding

Institutional Review Board Statement: Not applicable.

Informed Consent Statement: Not applicable

Data Availability Statement: In this section, please provide details regarding where data supporting reported results can be found, including links to publicly archived datasets analyzed or generated during the study. Please refer to suggested Data Availability Statements in section "MDPI Research Data Policies" at https://www.mdpi.com/ethics. You might choose to exclude this statement if the study did not report any data.

Acknowledgments: We acknowledge the late Prof. Dr. Gustavo Zubieta-Castillo (Sr. 1926-2015), our mentor and a world pioneer in chronic hypobaric hypoxia medicine and physiology. We also thank Lucrecia DeUrioste and Rafaela Zubieta-DeUrioste for their collaboration, support, and suggestions.

Conflicts of Interest: The authors declare no conflict of interest.

\section{References}

Zubieta-Calleja G, Zubieta-DeUrioste N. Acute Mountain Sickness, High Altitude Pulmonary Edema, and High Altitude Cerebral Edema: A view from the High Andes. Respir Physiol Neurobiol. 2021 Feb;287:103628.

Frisancho AR. Developmental functional adaptation to high altitude: Review. American Journal of Human Biology. 2013.

Storz JF, Scott GR. Life Ascending: Mechanism and Process in Physiological Adaptation to High-Altitude Hypoxia. Annual Review of Ecology, Evolution, and Systematics. 2019.

Blix AS. Adaptations to deep and prolonged diving in phocid seals. Vol. 221, The Journal of experimental biology. NLM (Medline); 2018.

Zubieta-Castillo GR, Zubieta-Calleja GR, Zubieta-Calleja L. Chronic mountain sickness: The reaction of physical disorders to chronic hypoxia. J Physiol Pharmacol. 2006;57(4):431-42.

Zubieta-Castillo G. Forever: Loss of Adaptation does not exist [Internet]. Altitudeclinic.com. 2010. Available online: http://altitudeclinic.com/blog/2010/07/forever-loss-of-adaptation-does-not-exist/ (Accessed on 12/5/2021)

Zubieta-Castillo, G. \& Zubieta-Calleja G. Variations in pulse oximetry in natives at high altitude (3510m) and after exposure to simulated sea level. Acta Andin [Internet]. 1996;2(1 special issue). Available online: https://www.altitudeclinic.com/oxivariations.html (Accessed on 12/5/2021) 
Zubieta-Calleja G. Human Adaptation to High Altitude and to Sea Level: Acid-Base equilibrium, ventilation and circulation in chronic hypoxia. VDM Verlag Dr. Müller; 2010.

Zubieta-Calleja GR, Zubieta-DeUrioste N. Space travel in a high-altitude environment. One more step in human BioSpaceForming. BLDE Univ J Heal Sci. 2018;3:97-103.

Zubieta-Calleja G, Zubieta-DeUrioste N. Space travel in a high altitude environment: Biology by-passing the pressure laws of physics and BioSpaceForming. Rev Cuba Investig Biomed. 2019;

Naeije R, Vanderpool R. Pulmonary hypertension and chronic mountain sickness. High Alt Med Biol. 2013;

Zubieta-Calleja GR, Zubieta-Castillo G, Zubieta-Calleja L, Zubieta-Calleja N. exercise performance in chronic mountain sickness (CMS) patients at 3510m. High Alt Med Biol. 2002;3:114-5.

Zubieta-Calleja GR, Zubieta-DeUrioste N, Venkatesh T, Das K, Soliz J. COVID-19 and Pneumolysis Simulating Extreme High-altitude Exposure with Altered Oxygen Transport Physiology; Multiple Diseases, and Scarce Need of Ventilators: Andean Condor'seye-view. Rev Recent Clin Trials. 2020;

Bodil Schmidt-Nielsen, editor. August \& Marie Krogh Lives in Science. Oxford: Oxford University Press; 1995.93 p.

Zubieta-Calleja GR, Paulev PE, Zubieta-Calleja L, Zubieta-Castillo G. Altitude adaptation through hematocrit changes. J Physiol Pharmacol. 2007;

Bren KL, Eisenberg R, Gray HB. Discovery of the magnetic behavior of hemoglobin: A beginning of bioinorganic chemistry. Vol. 112, Proceedings of the National Academy of Sciences of the United States of America. National Academy of Sciences; $2015 . \mathrm{p}$. 13123-7.

Zubieta-Calleja GR, Paulev PE, Zubieta-Calleja L, Zubieta-Calleja N, Zubieta-Castillo G. Hypoventilation in Chronic Mountain Sickness: A mechanism to preserve energy. J Physiol Pharmacol. 2006;

Paulev PE, Zubieta-Calleja GR. Essentials in the diagnosis of acid-base disorders and their high altitude application. J Physiol Pharmacol. 2005;56(SUPPL. 4):155-70.

Zubieta-Calleja G, Zubieta-Castillo G, Zubieta-Calleja L, Ardaya-Zubieta G, Paulev PE. Do over 200 million healthy altitude residents really suffer from chronic acid-base disorders? Indian J Clin Biochem. 2011;26(1):62-5.

Grocott MPW, Martin DS, Levett DZH, McMorrow R, Windsor J, Montgomery HE. Arterial blood gases and oxygen content in climbers on Mount Everest. N Engl J Med. 2009;360(2):140-9.

Zubieta-Calleja Jr G. Extremely high altitude hypoxic conditions during Mount Everest expeditions, residence at South Pole stations, in Tibet and among the Andes: Van Slyke equation modification is crucially important for acid-base measurements. J Biol Phys Chem. 2012;12(3):103-12.

Zubieta-Calleja G, Zubieta-Castillo G. Changes in Oximetry during Breath Holding in Normal Residents of High Altitude (3510m). In: Ohno H, Kobayashi T, Shigeru M, Nakashima M, editors. Progress in Mountain Medicine and HIgh Altitude Physiology. Press Committee of the 3rd World Congress on Mountain Medicine and High Altitude Physiology; 1998. p. 343-8.

Auerbach P, Miller YE. High Altitude Flatus Expulsion (HAFE). West J Med. 1981;

Frisancho O. Dolicomegacolon andino y vólvulos intestinales de altura. Rev Gastroenterol del Perú [Internet]. 2008 Jul [cited 2021 Apr 13];28(3). Available online: http://www.scielo.org.pe/scielo.php?script=sci arttext\&pid=S1022-51292008000300007 (Accessed on 12/5/2021)

Borda L, Kcam Mayorca E, Alarcon Aguilar P, Miranda Rosales L. Megacolon andino y vólvulo del sigmoides de la altura: Presentación de 418 casos entre 2008 - 2012 en el hospital C. Monge - Puno, Perú. Rev Gastroenterol del Perú [Internet]. 2017 [cited 2021 Apr 13];37(4). Available online: http://www.scielo.org.pe/scielo.php?script=sci_arttext\&pid=S1022$\underline{51292017000400004}$ (Accessed on 12/5/2021)

Savourey G, Launay JC, Besnard Y, Guinet A, Travers S. Normo- and hypobaric hypoxia: Are there any physiological differences? Eur J Appl Physiol. 2003;

Coppel J, Hennis P, Gilbert-Kawai E, Grocott MPW. The physiological effects of hypobaric hypoxia versus normobaric hypoxia: A systematic review of crossover trials. Extreme Physiology and Medicine. 2015.

Zubieta-Calleja GR, Ardaya G, Zubieta N, Paulev PE\&, G. Z-C. Tolerance to Hypoxia [Internet]. Vol. 59, J Fisiol. 2013. p. 65-71. Available online: https://zuniv.net/pub/TolerancetoHypoxiaFiziol.pdf (Accessed on 12/5/2021)

Zubieta-Calleja G, Zubieta-Castillo G. Tolerance to Hypoxia: A High Altitude Paradox. Wilderness Environ Med. 2015;

Zubieta-Calleja G, Zubieta-DeUrioste N. Low Altitude Peripheral Edema (LAPE): The Opposite of HAPE or HACE. Wilderness Environ Med [Internet]. 2017 Mar 1 [cited 2021 Apr 13];28(1):e3. Available online: http://www.wemjournal.org/article/S1080603217300182/fulltext (Accessed on 12/5/2021)

Pollard AJ, Durmowicz A, Durrer B, Eldridge M, Hackett P, Jean D, et al. Children at high altitude: An international consensus statement by an ad hoc committee of the International Society for Mountain Medicine, March 12, 2001. High Alt Med Biol. 2001;

Marticorena E, Hultgren HN. Evaluation of therapeutic methods in high altitude pulmonary edema. Am J Cardiol. 1979;

Suresh K, Shimoda LA. Lung circulation. Compr Physiol. 2016;

Semenza GL. Regulation of oxygen homeostasis by hypoxia-Inducible factor 1. Physiology. 2009.

Semenza GL. Oxygen Sensing, Homeostasis, and Disease. N Engl J Med. 2011;

Semenza GL. Hypoxia-inducible factor 1 (HIF-1) pathway. Science's STKE : signal transduction knowledge environment. 2007.

Lee JW, Ko J, Ju C, Eltzschig HK. Hypoxia signaling in human diseases and therapeutic targets. Experimental and Molecular Medicine. 2019.

Prabhakar NR, Semenza GL. Adaptive and maladaptive cardiorespiratory responses to continuous and intermittent hypoxia mediated by hypoxia-inducible factors 1 and 2. Physiological Reviews. 2012. 
Zubieta-Castillo, G. \& Zubieta-Calleja G. Triple Hypoxia Syndrome. Altitudeclinic.com. 1989.

Zubieta-Calleja G, Zubieta-DeUrioste N. Pneumolysis and “Silent Hypoxemia” in COVID-19. Indian J Clin Biochem [Internet]. 2020; Available online: https://doi.org/10.1007/s12291-020-00935-0 (Accessed on 12/5/2021)

Bärtsch P, Gibbs JSR. Effect of altitude on the heart and the lungs [Internet]. Vol. 116, Circulation. Lippincott Williams \& Wilkins; 2007 [cited 2021 Jun 11]. p. 2191-202. Available online: http://circ.ahajournals.org (Accessed on 12/5/2021)

Hultgren HN, Grover RF, Hartley LH. Abnormal circulatory responses to high altitude in subjects with a previous history of highaltitude pulmonary edema. Circulation [Internet]. 1971 [cited 2021 Jun 1];44(5):759-70. Available online: http://ahajournals.org (Accessed on 12/5/2021)

Coudert J. High-Altitude Pulmonary Edema. Med Sport Sci. 1985;19:99-102.

Maggiorini M, Mélot C, Pierre S, Pfeiffer F, Greve I, Sartori C, et al. High-altitude pulmonary edema is initially caused by an increase in capillary pressure. Circulation [Internet]. 2001 Apr 24 [cited 2021 Jun 1];103(16):2078-83. Available online: http://www.circulationaha.org (Accessed on 12/5/2021)

Dempsey JA, Morgan BJ. Humans in hypoxia: A conspiracy of maladaptation?! Physiology [Internet]. 2015 Jul 1 [cited 2021 Jun 1];30(4):304-16. Available online: https://pubmed.ncbi.nlm.nih.gov/26136544/(Accessed on 12/5/2021)

Ulloa NA, Cook J. Altitude Induced Pulmonary Hypertension [Internet]. StatPearls. StatPearls Publishing; 2020 [cited 2021 Jun 1]. Available online: http://www.ncbi.nlm.nih.gov/pubmed/32310385 (Accessed on 12/5/2021)

Antezana G, Barragán L, Coudert J, Coudkowicz L, Durand J, Lockhart A, et al. The Pulmonary Circulation of High Altitude Natives. In Springer, New York, NY; 1982 [cited 2021 Jun 1]. p. 142-9. Available online: https://link.springer.com/chapter/10.1007/978-14612-5639-7 19 (Accessed on 12/5/2021)

Zubieta-Calleja G, Zubieta-DeUrioste N. Extended longevity at high altitude: Benefits of exposure to chronic hypoxia. BLDE Univ J Heal Sci. 2017;

Honigman B. Study shows living at high altitude reduces risk of dying from heart disease I EurekAlert! Science News [Internet]. Eurekalert. 2011 [cited 2021 May 18]. Available online: https://www.eurekalert.org/pub releases/2011-03/uocdss1032511.php (Accessed on 12/5/2021)

Saxer S, Schneider SR, Appenzeller P, Bader PR, Lichtblau M, Furian M, et al. Asthma rehabilitation at high vs. low altitude: randomized parallel-group trial. BMC Pulm Med. 2019;

Simeonov KP, Himmelstein DS. Lung cancer incidence decreases with elevation: Evidence for oxygen as an inhaled carcinogen. PeerJ [Internet]. 2015 [cited 2021 May 18];2015(1). Available from: /pmc/articles/PMC4304851/

Merrill RM, Frutos A. Reduced Lung Cancer Mortality With Lower Atmospheric Pressure. Dose Response [Internet]. 2018 Apr 1 [cited 2021 May 18];16(2):1559325818769484. Available online: http://www.ncbi.nlm.nih.gov/pubmed/29706845 (Accessed on 12/5/2021)

Zubieta-Calleja G. The advantages of ultraviolet radiation in controlling the coronavirus at high altitude [Internet]. 2020 [cited 2020 Jul 28]. Available online: http://altitudeclinic.com/blog/2020/04/u v-radiation-covid-2-at-high-altitude/ (Accessed on 12/5/2021)

Accinelli RA, Leon-Abarca JA. At High Altitude COVID-19 Is Less Frequent: The Experience of Peru. Arch Bronconeumol. 2020;

Cano-Perez E, Torres-Pacheco J, Fragozo-Ramos MC, Garcia-Diaz G, Montalvo-Varela E, Pozo-Palacios JC. Negative correlation between altitude and COVID-19 pandemic in Colombia: A preliminary report. Am J Trop Med Hyg [Internet]. 2020 Dec 1 [cited 2021 Apr 15];103(6):2347-9. Available online: https://www.dane.gov.co/index.php/estadisticas-por-tema/ (Accessed on $12 / 5 / 2021)$

Arias-Reyes C, Carvajal-Rodriguez F, Poma-Machicao L, Aliaga-Raduán F, Marques DA, Zubieta-DeUrioste N, et al. Decreased incidence, virus transmission capacity, and severity of COVID-19 at altitude on the American continent. PLoS One. 2021;16(3):e0237294.

Arias-Reyes C, Zubieta-DeUrioste N, Poma-Machicao L, Aliaga-Raduan F, Carvajal-Rodriguez F, Dutschmann M, et al. Does the pathogenesis of SARS-CoV-2 virus decrease at high-altitude? Respir Physiol Neurobiol. 2020;277:103443.

1. Author 1, A.B.; Author 2, C.D. Title of the article. Abbreviated Journal Name Year, Volume, page range.

2. Author 1, A.; Author 2, B. Title of the chapter. In Book Title, 2nd ed.; Editor 1, A., Editor 2, B., Eds.; Publisher: Publisher Location, Country, 2007; Volume 3, pp. 154-196.

3. Author 1, A.; Author 2, B. Book Title, 3rd ed.; Publisher: Publisher Location, Country, 2008; pp. $154-196$.

4. Author 1, A.B.; Author 2, C. Title of Unpublished Work. Abbreviated Journal Name stage of publication (under review; accepted; in press).

5. Author 1, A.B. (University, City, State, Country); Author 2, C. (Institute, City, State, Country). Personal communication, 2012.

6. Author 1, A.B.; Author 2, C.D.; Author 3, E.F. Title of Presentation. In Title of the Collected Work (if available), Proceedings of the Name of the Conference, Location of Conference, Country, Date of Conference; Editor 1, Editor 2, Eds. (if available); Publisher: City, Country, Year (if available); Abstract Number (optional), Pagination (optional).

7. Author 1, A.B. Title of Thesis. Level of Thesis, Degree-Granting University, Location of University, Date of Completion.

8. Title of Site. Available online: URL (accessed on Day Month Year). 